\title{
Paris romantique 1815-1848
}

\section{Lise Sabourin}

\section{(2) OpenEdition}

\section{Journals}

\section{Édition électronique}

URL : https://journals.openedition.org/studifrancesi/43959

DOI : $10.4000 /$ studifrancesi.43959

ISSN : 2427-5856

\section{Éditeur}

Rosenberg \& Sellier

\section{Édition imprimée}

Date de publication : 1 juin 2021

Pagination : 223-224

ISSN : 0039-2944

\section{Référence électronique}

Lise Sabourin, «Paris romantique 1815-1848». Studi Francesi [En ligne], 193 (LXV | I) | 2021, mis en ligne le 01 juillet 2021, consulté le 15 octobre 2022. URL : http://journals.openedition.org/studifrancesi/ 43959 ; DOI : https://doi.org/10.4000/studifrancesi.43959

\section{Ce document a été généré automatiquement le 15 octobre 2022}

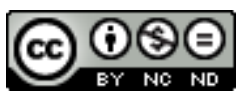

Creative Commons - Attribution - Pas d'Utilisation Commerciale - Pas de Modification 4.0 International - CC BY-NC-ND 4.0

https://creativecommons.org/licenses/by-nc-nd/4.0/ 


\title{
Paris romantique 1815-1848
}

\author{
Lise Sabourin
}

\section{RÉFÉRENCE}

Paris romantique 1815-1848, Musée de la Vie romantique - Petit Palais Musée des BeauxArts de la ville de Paris, Paris Musées, 2019, 512 pp.

1 Cette importante exposition présentée au Petit-Palais de Paris, en coopération avec le Musée de la Vie romantique, donne à voir le Paris romantique que les travaux d'Haussmann ont rendu difficile à imaginer aujourd'hui.

2 Après une introduction (pp. 15-39) sur Paris et le pouvoir (qui paracheva les constructions commencées sous Napoléon), où nous parcourons le Paris monumental des romantiques (de la Bastille aux Champs-Élysées), essentiellement néo-antique, au fil d'une petite histoire du flâneur parisien, souvent artiste, parfois étranger, le tableau s'organise en neuf sections.

3 Le promeneur se trouve emmené d'abord au Palais des Tuileries (pp. 40-71) pour comprendre que sous les Bourbons, de la branche aînée (voir le goût de la duchesse de Berry) comme cadette (avec la sculptrice Marie d'Orléans, Ferdinand-Philippe d'Orléans et Louis duc de Nemours), «l'éclectisme [fut] notre goût» comme disait Musset.

4 Puis nous entrons au Palais-Royal (pp. 72-135), haut lieu des restaurants et cafés, du commerce de luxe et des modes pour les dandys et les parisiennes, comme le montrent les créations des costumiers, joailliers, porcelainiers, cristalliers, horlogers, tabletiers et bronziers.

5 Au Louvre (pp. 136-195) se tient le Salon, lancé dès l'effondrement de l'Empire, comme une compensation à l'occupation étrangère, qui triomphe à l'époque romantique, avec ses sujets mythologiques, ses paysages méditerranéens, ses portraits, sa peinture religieuse et historique (en faveur des causes grecque ou polonaise, mais aussi à propos d'Henri IV et Napoléon), portées par l'inspiration littéraire de Rousseau, Mme de Staël, l'Arioste, Goethe, Byron, Shakespeare, Chateaubriand et Hugo. 
6 Le coup de projecteur qu'il donna sur Notre-Dame de Paris (pp. 196-231) a suscité la création du Musée des monuments français et l'invention du Vieux Paris, qui sauva notamment l'hôtel de Cluny, mais aussi l'engouement des aquarellistes anglais (Bonington, Boys, Wyld, Davis) et, sous l'impulsion de Mérimée, le goût pour le gothique (avec le fameux style «à la cathédrale» du cabinet de la comtesse d'Osmond ou de maintes pendules comme de papiers peints).

7 En 1830, la capitale est aussi le Paris des révolutions (pp. 232-287), avec les Trois Glorieuses (célébrées par Les Drapeaux de Léon Cogniet) qui déclenchèrent une «fièvre caricaturale» politique sous la Monarchie de Juillet («Philipon contre Philippe», disaiton plaisamment), déjà initiée par Hernani et ses trente-trois batailles (plutôt qu'à sa première), confirmée par la symphonie fantastique de Berlioz, si novatrice orchestralement dans son évocation des épisodes de la vie d'artiste. Il ne faut pas oublier non plus tous les monuments politiques érigés durant cette période: la Chapelle expiatoire (élevée sur le lieu où reposèrent de 1815 à 1827 Louis XVI et MarieAntoinette), la Colonne de Juillet à la Bastille (remaniée de cénotaphe des victimes en hommage aux soldats tombés), l'achèvement de l'Arc de Triomphe (avec son programme sculptural contrasté), l'embellissement de la Place de la Concorde (par le placement de l'obélisque, des fontaines et des grandes villes de France), la longue définition de la Madeleine (d'abord temple à la Grande Armée, monument expiatoire sous Louis XVIII, finalement église sous Louis-Philippe), le tombeau de l'Empereur (qui suscita le débat par la suppression du chœur des Invalides), l'érection de la colonne Vendôme (et ses diverses versions de l'image napoléonienne).

Du Quartier latin aux Barrières (pp. 288-333) se déroule la vie de bohème rendue célèbre par Henry Murger, qu'illustrent les bals publics fréquentés notamment par étudiants et grisettes (dont s'inspire Mimi Pinson et que représentent Gavarni et Monnier). La frénésie de danses (polka, valse, contredanse, quadrille, galop, cancan) n'empêche pas d'autres plaisirs: la promenade masquée «d'usage», puis le pandémonium costumé au bal de l'Opéra, les déguisements du carnaval qui se terminent par le défilé du Bœuf gras et la descente de la Courtille. C'est tout ce peuple romantique, un temps porté par le saint-simonisme, ce Nouveau Christianisme (1832), que chante Béranger, que narrent Paul de Kock et Eugène Sue.

9 Mais il est d'autres lieux de satisfactions, plus intellectuelles tout en restant enjouées, dans les cénacles et les salons littéraires, de l'Abbaye-au-Bois à l'Arsenal (pp. 334-359), autour de Mme Récamier et Chateaubriand, Nodier, Hugo, chez Delphine de Girardin ou au club des haschischins de l'hôtel Pimodan. David d'Angers par ses médaillons nous a laissé tous les visages de son «Panthéon personnel» qui est devenu collectif, tandis que les charges de Roubaud et Grandville les situent dans leur course à la célébrité.

10 Les nouveaux quartiers, Chaussée d'Antin et Nouvelle Athènes (pp. 360-409), se remplissent d'artistes à partir de 1827, mais surtout en $31,34,40$ et 44, de courtisanes, de lorettes et de peintres, et aussi de photographes (Daguerre) et de musiciens (Liszt sur piano Erhard, Chopin sur Pleyel, Paganini et Thalberg, le professeur Zimmermann, Luisa Puget et ses romances), tandis que le «Dantanorama» des statuettes caricaturales et les collections de l'hôtel James de Rothschild deviennent emblématiques d'un marché de l'art en pleine expansion grâce aux achats des mécènes et au développement des galeries de peintures et des reproductions de bronzes.

11 Enfin triomphe le spectacle, des grands boulevards, avec les affiches des petits théâtres de mélodrame ou de vaudeville, mais aussi au Théâtre-Français (pp. 410-492), et, dans la 
foulée du drame romantique (Dumas, Hugo Vigny, Delavigne), les grands décorateurs satisfont le goût du visuel avec de magnifiques mises en scène pour le grand opéra (Rossini, Meyerbeer, Halévy, Bellini, Donizetti, Berlioz, Verdi), le ballet romantique (Robert le diable, La Sylphide, Gustave III, Le Diable boiteux, Giselle, La Filleule des fées), l'opéra-comique (Boieldieu, Auber, Adam, Hérold), le Théâtre-Italien (avec la Pasta, la Malibran, Pauline Viardot) ou le théâtre anglais, sans oublier le diorama de Louis Daguerre.

12 L'épilogue souligne que la Révolution de 1848 (pp. 493-497), bouffée de violence et de liberté, ne fut architecturalement pour Paris qu'un bref prélude à la profonde mutation réalisée par le Second Empire. 